\title{
RE KEVIN In PeRspective
}

\section{RACHAEL WALLBANK}

[2004] DeakinLRev 461; (2004) 9(2) Deakin Law Review 461

This article discusses the evolution of the common law concerning the phenomenon of transsexualism while seeking to identity the place occupied in that process by the decision of Justice Richard Chisholm (as he then was) in Re Kevin: Validity of Marriage of Transsexual [2001] FamCA 1074 ('Re Kevin') and the affirming decision of the Full Court of Family Court of Australia in respect of the appeal of that decision in The Attorney-General for the Commonwealth $\mathrm{v}$ "Kevin and Jennifer" and Human Rights and Equal Opportunity Commission [2003] FamCA 94 ('Re Kevin-Full Court'); collectively referred to as 'the Re Kevin decisions'. The article examines the phenomenon of transsexualism, associated language, terminology and causation issues as well as discussing the legal rights of young people in respect of medical treatment for transsexualism aided by a critique of the Australian decision Re Alex - Hormonal Treatment for Gender Identity Dysphoria [2004] FamCA 297.

\section{INTRODUCTION}

Transsexualism is a form of human diversity in sexual formation, reported since antiquity, in which an individual experiences her or himself to be of the sex opposite to that indicated by the individual's original sexually differentiated body combined with a compelling need to alter that sexually differentiated body in order

\footnotetext{
* Principal, Wallbanks. The author represented and appeared as counsel on behalf of 'Kevin' and 'Jennifer' in Re Kevin, both at trial and on appeal, with the significant assistance throughout of Ms T J Anderson, barrister, Sydney. Further material and pleadings concerning the Re Kevin proceedings as well as articles by the author, biographical information, useful references and links are available at the Resources and Links section of the author's firm's website <http://www.wallbanks.com> .
} 
to bring it into better harmony with the individual's innate sexual identity (otherwise called neurological, psychological or brain sex). ${ }^{1}$

Such a discussion necessarily involves the story of the struggle for human rights of the people who live this particular example of difference in human sexual formation. That story is continuing to unfold in various ways throughout the world and is experiencing a particularly rich period. A review of the medical science, case law and legislation affecting people living with transsexualism around the planet indicates, as one might expect, that different cultures experience and respond to the phenomenon of transsexualism in different ways in the same way that transsexualism triggers a significant range of different personal reactions. In a world struggling with difference, the phenomenon of transsexualism is to the health of cultures what the canary was to the air quality of mines.

The more I learn about this subject, the more similarities I see between the struggle of people who experience transsexualism (and their families) for human rights and the Civil Rights Movement in the United States of America. The marriage of Sydney couple, 'Kevin' and 'Jennifer' ${ }^{2}$ on $21^{\text {st }}$ August 1999, in defiance of the advice of the Commonwealth Attorney General's Department that they had no right to marry (and that 'Kevin' would commit a criminal offence if he tried to do so), and their subsequent successful legal battle to pursue their human and civil rights against the Australian Government which commenced $18^{\text {th }}$ October 1999, echo the refusal of Rosa Parks to give up her seat to a white man on a bus in Montgomery, Alabama, USA on Thursday, $1^{\text {st }}$ December 1955, her arrest and the successful legal battle for civil rights for African Americans that followed.

Both these human rights struggles are international and ongoing. Both have involved court proceedings, a struggle for legislative reform and medical argument concerning the legal and social recognition of these minority peoples as legitimate human beings with equal rights; rather than being assigned a lesser status due to the colonised mystification and distortion of their reality by the dominant culture. The discrimination and harm suffered by both such minorities because of their difference have driven some of their members to deny their own being through the use of 'stealth' and 'passing, ${ }^{3}$ as social survival methods. Finally, both these legal and human rights struggles are about seeking to rehabilitate and claim legitimate identity in the world; and at that fundamental level both have required minority

\footnotetext{
${ }^{1}$ Substantial information, resources and links concerning transsexualism generally and its aetiology can be accessed at the Australian WOMAN Network website at 〈http://www.w-o-m-a-n.net>. Lynn Conway's site at <http://www.lynnconway.com> is excellent for an appreciation of the history of transsexualism (although she uses the term "transgender" interchangeably with "transsexualism" in the American way). People living with transsexualism were undergoing sex affirmation surgery since ancient times.

${ }^{2}$ Pseudonyms used to protect identity. See also Family Law Act 1975 (Cth) s 121.

${ }^{3}$ See Appendix A for a description of passing contained in an excerpt from the essay by Sandy Stone,

'A Post transsexual Manifesto', in Julia Epstein and Kristina Straub (Eds) Body Guards (1991) 298-299.
} 
group members finding their own prejudice-free language with which to tell the world their stories and be understood afresh.

It is really no wonder that transsexualism remains so difficult to approach academically; involving such a multidisciplinary medicolegal/sociological landscape covered by a fog of mystified, medicalised and prejudiced language. In the circumstances, I have sought to guide the reader to a clearer perspective from which to consider the place occupied by the Re Kevin decisions through first briefly discussing the predicament of transsexualism itself, the issues concerning language and terminology and the historic debate concerning the causation of transsexualism, before finally looking at the place occupied by the Re Kevin decisions in the common law heritage of Australia, New Zealand, the United States of America and the United Kingdom concerning transsexualism. Finally, I deal with the issue of the care, welfare and legal rights in respect of medical treatment of children and adolescents with transsexualism.

\section{BACKGROUND}

Although debate exists as to the number of people with transsexualism in any cultural group, it is reasonable to assume that there are at least about 5,000 people of all ages with transsexualism in Australia. ${ }^{4}$ Underestimation of numbers is common throughout the world due the effects of shame and secrecy. Suicide and lessor forms of self-harm, in young and old alike, caused by the experience of the difference of transsexualism generally go unidentified as such.

People with transsexualism have families and often have children. Many people with transsexualism (together with their family members and loved ones) live out their lives in secrecy because of their fear of how society (and their neighbour) will deal with them in the event that they disclose the existence, or the history, of their transsexualism. This is particularly the case when children and adolescents affirm a sex different to that to which they were first assigned.

The survival method called 'stealth' is a version of "passing" but embodies one's living one's public life in denial of one's experience of transsexualism. The bargain of choosing to live a false and secret existence in order to live free of physical harm and/or prejudice that is the act of 'passing' should be familiar to most as it is something most of us are obliged to do in intermittent and small ways on a daily basis to satisfy our culture's rapacious demand for conformity. Passing is the same activity undertaken by some 'people of colour' who have permitted themselves to

\footnotetext{
${ }^{4}$ Lynn Conway, How Frequently Does Transsexualism Occur? Available on-line at: <http://www.lynnconway.com/>
} 
be mistaken for 'white' in order to avoid the prejudicial treatment they would have otherwise received.

For a variety of reasons, including culturally cultivated shame, ignorance, the desire to procreate, good intentions and the erroneous medical advice that transsexualism is treatable by denial, many people with transsexualism only affirm their innate sex later in life and after they have married, formed de facto relationships and/or borne children in their first assigned sex. Again, because of shame, such sex affirmation may well come as a surprise to partners, children, parents, other family members, in-laws, workmates, colleagues and employers. The reaction to the revelation of an individual's sex affirmation can range from appreciation and support to condemnation and rejection in a culture where, at worst, ignorance of transsexualism is rife and, at best, transsexualism is likely to be confused with other phenomena such as transgender expression, transvestism or sexuality.

Significant parenting and social issues can accompany a parent's sex affirmation. Sex affirmation, often occurring at or near separation, can result in a substantial loss of income, if not gainful employment, for the person with transsexualism. The total medical costs of sex affirmation treatment (still not publicly funded in Australia, although it is in the United Kingdom) can amount to as much as AUD\$50,000.00. People with transsexualism die or their lives are abused and degraded by their efforts to fund the price of such treatment. As normal employment is often lost as a result of an individual's sex affirmation, many younger people with transsexualism turn to prostitution or other crime in their desperation to fund sex affirmation treatment. Many, too old for prostitution, ostracised by family, friends and culture and without the monetary means to attain treatment for their transsexualism, suffer severe depression, self-harm and often take their own lives. Difference can be a health hazard. Shame kills.

Children and adolescents with transsexualism suffer in their dependency. The voices of these young people, from pre-puberty to adulthood, clearly stating their predicament and seeking help, are too often ignored, ridiculed or interpreted as illness or disorder; not only by their parents and family members but by wellmeaning members of the medical, legal and health care professions. I do not intend to be simplistically critical of the hard working medical practitioners and others who have sought to assist people with transsexualism. My contention is that the error of the disorder model of transsexualism and the continued association of transsexualism with pathology through the use of such terms as Gender Dysphoria and Gender Identity Disorder is the result of cultural, rather than individual, prejudice born of a pan-cultural genitocentrism ${ }^{6}$ that finds the difference of transsexualism almost too challenging to tolerate or accept.

\footnotetext{
${ }_{6}^{5}$ Stone, above n 3, 298.

${ }^{6}$ Meaning centred upon the genitalia as the factor of sexual differentiation that determines an individual's sex. For an interesting analysis of this concept and the history and debate in respect of the causation (natural/organic or pathological) see Andrew N Sharpe, Transgender Jurisprudence, Dysphoric Bodies of Law (2002) 39.
} 
In order to receive treatment for their transsexualism, such young people (and their parents/guardians) must negotiate their way through the malaise of outdated medical and legal categorisations of childhood and adolescent transsexualism; which both mystify and pathologise their diagnosis and prejudice their treatment.

In Australia, as a result of the recent decision of Re Alex-Hormonal Treatment for Gender Identity Dysphoria, ${ }^{7}$ young people with transsexualism and their parents/guardians are required to obtain the approval of the Family Court of Australia, exercising its child welfare jurisdiction, before such children and adolescents can receive medically approved nonsurgical hormonal and other treatment for their condition; notwithstanding that such treatment is also approved by the children's parents. Before Re Alex the conservative non-surgical medical treatment for transsexualism that is normally followed in childhood and adolescence was available with parental consent upon proper and thorough diagnosis by medical practitioners under States' child welfare legislation. ${ }^{8}$

People living with transsexualism undergo irreversible sex affirmation treatment (including genital surgery) on their own initiative because of their need to experience sexual harmony between body and mind and not because of any legal requirement. This distinguishing aspect of transsexualism, and the consequential medico legal reform sought by people living with transsexualism, were not explored or adequately acknowledged in Re Alex.

As $R e$ Alex came after the Re Kevin decisions, but represents a significantly different perception of transsexualism, at least as manifested in young people, and has been interpreted so as to give rise to considerable hardship for such young people and their parents seeking such treatment, I will deal with that decision separately.

The experience of transsexualism, even in a culture conceived of as compassionate, remains the experience of ongoing significant and sometimes life-threatening personal, social, educational, medical and legal crises. The predicament is made worse by a lack of public funding for medical treatment and a pervasive ignorance and/or misconception amongst members of the medical profession as to the nature of transsexualism existing in a public policy vacuum and an absence of truly equal or complete civil rights.

The Commonwealth of Australia and its States have no uniform legislation dealing with intersexual rights, including those of people with transsexualism, and the

\footnotetext{
${ }^{7}$ [2004] FamCA 297 (13 April 2004) ('Re Alex').

${ }^{8}$ The author is in possession of the legal advice NSW Health to that effect, which has been relied upon by NSW Health to deny and suspend the provision of medical treatment for transsexualism in childhood and adolescence in NSW, which had been approved prior to the decision in $\boldsymbol{R} \boldsymbol{e}$ Alex, pending such young people's parents making successful individual applications to obtain the authorisation of the Family Court of Australia.
} 
reassignment/alteration/correction of the legal $\operatorname{sex}^{9}$ of such individuals. All States now have legislation that, subject to certain inhumane conditions, enables people with transsexualism and other intersexual conditions who have undergone irreversible sex affirmation (re-assignment) treatment to effect a re-assignment of their legal sex. ${ }^{10}$ In Australia, once a person's legal sex has been reassigned the person is legally of the re-assigned sex.

A statutory obligation is imposed upon the Registrars of each Australian State or Territory, who maintain the records of our legal particulars (including our assigned legal sex) that such records be contemporaneously accurate. Australian civil and criminal authorities, as well as the public, rely upon the contemporaneous accuracy of such particulars which are evidenced by the issue of a certified Birth Certificate. To be found to be representing oneself contrary to such particulars can have increasingly dire consequences in a world where legal identity, legality and security are interdependent concepts.

People with transsexualism and other intersexual people who have undergone irreversible sex affirmation treatment have only been permitted to correct or update the particulars as to their legal identity if they comply with such inhumane and strange conditions as the requirement they divorce their life-long spouse; ${ }^{11}$ but people in legally recognised de facto relationships are not required to terminate their relationships in order to have their legal sex re-assigned. Here married people with transsexualism fall victim to a misplaced legally expressed homophobia that fails to appreciate the workings of the marriage law of Australia, as clarified in $R e$ Kevin, that the validity of a marriage, and hence the sex of the parties to a marriage, are to be determined as at the date of the marriage. The 'sex of the parties' means their common law sex and does not require or invite some scientific investigation and or argument as to which (or which set) of the sexually differentiated aspects of a person determine their possibly multi-faceted biological sex. The withholding of the right to an accurate legal identity from a person of transsexual background because that person desires to continue to honour a marriage that has endured their transsexualism has nothing to say about the sex (or sexuality) of the couple at the time of the marriage and is clearly inhumane and against the public interest that would seek to honour an enduring marriage.

Other people living with transsexualism, such as children (other than infants), who through the circumstances of age or health are simply unable to undergo irreversible

\footnotetext{
${ }^{9}$ The Legal Sex of a person means the sex which is usually first assigned to the person at near the birth event by a medical practitioner as a result of a casual inspection of the person's external genitalia (only) and which is recorded amongst the particulars of the legal identity of that person in the register (in Australia called the 'Register of Births, Deaths and Marriages') maintained for that purpose by States. Such particulars are evidenced by, or published as, the person's birth certificate.

${ }^{10}$ Victoria, which introduced legislation in 2004 for the reassignment of legal sex, was the last State to do so.

${ }^{11}$ SCAG (The States Council of Attorney's General) has had this issue on its agenda for many years without result.
} 
sex affirmation treatment, are precluded from the right to have their legal sex reassigned.

There seems to me to be no good legal or public policy reason why a married person should not be able to have her or his legal sex reassigned. There are several such policy considerations to recommend the removal of that inhumane prohibition. Similarly, there is no legislative impediment of which I am aware that would prevent the creation by States of a dual regime for the reassignment of legal sex whereby those people who have undergone irreversible sex affirmation treatment need only evidence that treatment to a State Registrar in order to have their legal sex reassigned, while those unable to do so because of conditions of health or age could make an exceptional application to an expert panel evidencing their predicament in order to have their legal sex reassigned, on either a permanent or provisional basis, on the ground of hardship. After all, law makers in medieval times were able to provide laws for the reassignment of legal sex of a person whereby in adulthood and prior to marriage, a person could, by sworn "promissionary oath", publicly renounce one sex and declare an oath to exclusively adhere to the other for the rest of his or her life. ${ }^{12}$

We live at a time when biological sex is increasingly being recognised as diverse and multidimensional (making understandable the existence of intersexual human beings) and where the assignment of legal sex can be mistaken and corrected. By the time of the Sydney Olympic Games chromosomal sex testing had been abandoned, due to the acceptance by the IOC that there were simply too many genuine female athletes who possessed "Y" chromosomes competing. By the time of the Athens Olympics the IOC had moved to permit people with transsexualism who had undergone sex affirmation surgery to compete in their affirmed sex.

Legally, we need to be able to identify and distinguish between an individual's predominant biological sex, legal sex, and common law sex (the sex declared/ declarable by a court for certain purposes) in order to properly consider the legal predicament of people living with transsexualism and other intersexual conditions.

Thus, one can begin to expand the possibilities of intersexuality in human beings while accepting that the question of whether one is able to live a reasonable life as a male or a female is ultimately determined by one's brain-sex differentiation rather than the appearance of one's genitalia and/or other sexually differentiated body parts. To quote Professor Milton Diamond concerning biologically derived sexual identity: 'It's what's between the ears that counts and not what's between the legs'.

And while a more subtle appreciation of the biology of sexual determination may assist, it is well to remain aware that the test for the determination of an individual's legal and common law sex and (and legal gender in the UK), and whether an

${ }^{12}$ Peggy T Cohen-Kettenis and Friedemann Pfafflin, 'Transgenderism and Intersexuality in Childhood and Adolescence - Making Choices' (2003) 155. 
individual's legal sex can be re-assigned, are each different from one another and are each different again from those concerning an individual's biological sex.

Legal categorisations and classifications are as least as much cultural as they are biological considerations. To quote Chisholm $\mathrm{J}$ in Re Kevin '...the fundamental task of the law..., in a legal and social context that divides all human beings into male and female, is to assign individuals to one category or the other, including individuals whose characteristics are not uniformly those of one or other sex. ${ }^{13}$ After all, stripped of its mystery, the first assignment of infant's legal sex is as much a cultural and legal act as it is a biological one.

As we permit transsexualism to be perceived in our culture as a natural aspect of human diversity, rather than a disorder, increasing numbers of people with transsexualism of all ages (and their parents/families/loved ones) are seeking to pursue their legal and human rights in respect of issues relating to education, relationships, wills, estates, discrimination and identity.

The good news is that, from individuals to government, people around the world are demonstrating an increasingly comprehensive capacity to appreciate the predicament of transsexualism and a willingness to assist people with transsexualism to live full lives. ${ }^{14}$ I was delighted recently when a senior legal officer of the New South Wales Education Department coined the name "Safe and Successful" to describe the policy we are seeking to develop in order to assist young people with transsexualism in New South Wales government schools.

\section{LANGUAGE}

Language and terminology represent a major obstacle for anyone seeking to understand and meaningfully discuss this subject because the language that has developed with regard to transsexualism has been affected by the impact of longstanding diverse cultural prejudice, ignorance and mystification; whether or not that language has been the creation of medicine, law or community.

As for any colonised people, and as it was for Civil Rights activists, the challenge for people with transsexualism is to find and express their own stories and identity in their own language reflective of their own experience of life rather than that of

\footnotetext{
${ }^{13}$ Re Kevin [2001] FamCA 1074, [315].

${ }^{14}$ The Gender Recognition Act 2004 in the United Kingdom, although problematic, is also evidence of this welcome trend, as is the progress made in Iran where the Islamic government has recognised transsexualism, allows its citizens to undergo sex affirmation treatment with surgery funded by the state, and issues new birth certificates in the affirmed sex. Iran's Muslim clerics, who dominate the judiciary, are becoming considerably better informed about transsexualism. Some clerics now even recommend sex affirmation treatment with surgery to those whom they consider suffer from transsexualism. The issue was discussed at a conference in Tehran in June 2004 that drew officials from other Persian Gulf countries.
} 
the normative or dominant culture. In their seemingly never-ending 'identity debates', people with transsexualism are, in fact, undergoing the difficult but necessary process of finding and developing their own meanings and language concerning transsexualism.

In Australia that process was stimulated by the experience of the Re Kevin proceedings and the detailed trial and appeal decisions; which required the expression of the experience of transsexualism to the Family Court of Australia and the general public in a demystified and intelligible way.

Neither the United Kingdom or the United States of America, the other prime places of language development in the English speaking world with regard to transsexualism, have developed anywhere near as rich or consistently affirmative a common law and legislative tradition in respect of transsexualism as that of Australia. In my view, Australia's distinct and developing language usage in respect of transsexualism, substantially nurtured by that socio/legal tradition, should be of interest worldwide in terms of its affirmation, clarification and creativity. I have sought to use such affirmative language throughout this article - including the following significant terms:

- People (or a person) living with transsexualism - is used rather than the demeaning objectifying noun "transsexual";

- A person is said to have affirmed their (innate) sex - rather than "transitioned (public sexes), when a person with transsexualism seeks to live a public life consistent with their innate or neurological sex rather than their first assigned legal sex;

- legal sex - is used to describe the sex of a person recorded in a register with the other legally identifying particulars of that person maintained in Australia by the States' Registrars of Births, Deaths and Marriages. A person's legal sex is usually assigned at or near their birth event and is evidenced by the person's birth certificate, ${ }^{15}$

- A person living with transsexualism who has affirmed the female sex after having been first assigned to the male legal sex is referred to as a female with transsexualism or an affirmed female rather than a "male-to-female transsexual" or an "MtF". Similarly, a person living with transsexualism who has affirmed the male sex in contradiction to the person's first assigned female legal sex is referred to as a male with transsexualism or an affirmed male rather than a "female-to-male transsexual" or an "FtM";

- All that therapy and medical treatment involved in the rehabilitative process of harmonising a person's sexually differentiated body with the person's sexually differentiated mind, including hormonal treatment, counselling, hair removal, voice training and surgery in respect of both genitalia and secondary sexual characteristics such as breasts is referred to as sex affirmation treatment. Such treatment should also properly involve

\footnotetext{
${ }^{15}$ See above $\mathrm{n} 9$ for a detailed description.
} 
(but almost never does), as a social aspect, assistance to family, friends, school, work and other key environments in appreciating the difference of transsexualism. The surgical aspect of this treatment, and specifically the genital surgery, is referred to as sex affirmation surgery rather than "sex reassignment surgery" or "genital reassignment surgery";

- Once a person has undergone irreversible sex affirmation treatment (including sex affirmation surgery) such a person is said to be a person of transsexual background (or history).

Those interested in a more thorough treatment of terminology in respect of transsexualism may find my paper, 'Difference on Trial - Transsexualism in Family Law and De Facto Relationships Litigation' ${ }^{16}$ more useful.

Clarity requires that an adequate distinction be made between transsexualism and other phenomena such as transgender expression, transvestism/cross-dressing and sexuality, as well as mental disorders properly described as Gender Dysphorial Gender Identity Disorder, and the development of a better cultural appreciation of the shared biological continuum occupied by transsexualism and other intersexual variations in human sexual formation. To do so is not to seek to devalue or offend any person so described, but only to better and properly express the true diversity of humanity in respect of sexuality, gender expression, sexual identity and mental health.

For the purpose of this paper, and in an effort to seek common ground and meaning, I will generally adopt the usage/categorisation followed by the respected United Kingdom legal academic and 'trans' rights campaigner Stephen Whittle. ${ }^{17}$ Whittle effectively rejects the use of 'transgender' as a 'one-size-fits-all' descriptor of difference associated with appearance and uses the terms trans, transgender and transsexual as exact terms and distinct categories - described as follows using affirmative language:

- Trans - those people who do not perceive of, or present, their gender identity in accordance with their first assigned legal sex, but who do not seek to live as, or identify as, other than the sex to which they were first assigned. Cross-dressers (transvestites) are included in this group.

- Transgender - all those people who live, or desire to live, a large part of their life in the role or dress of that gender opposite to that associated with the legal sex to which they were first assigned but who, unlike people with transsexualism, do not need or desire complete and irreversible sex affirmation treatment and, in particular, sex affirmation surgery and are a subgroup of the 'trans community'.

\footnotetext{
${ }^{16}$ Prepared for and published by the Family Law Section of the Law Council of Australia for Family Law 2004 - see their website; <http://www.familylawsection.org.au> or see the resources section of the author's website: 〈http://www.wallbanks.com>

${ }^{17}$ Stephen Whittle, Respect and Equality - Transsexual and Transgender Rights (2002) xxii-xxiii.
} 
While I agree with the distinction Whittle makes between trans, transgender and transsexualism, I do not share Whittle's opinion that people living with transsexualism, like those who live transgender, '...belong(s) to a sub-group of (the) trans community. ${ }^{18}$ Beyond the experience of prejudice related to appearance, I do not perceive any shared experience or continuum existing between the people defined within Whittle's category of trans and people living with transsexualism. ${ }^{19}$

Transsexualism's common ground is within the intersexual continuum; especially having regard to the shared experience and need of a broad group of people within that continuum concerning medical treatment, surgery and the reassignment of legal sex as well as the consequent issues of medical and legal/human rights reform; especially in respect of young people. ${ }^{20}$

Some transgender advocates fear and/or reject reliance upon a biological explanation for transsexualism even though no other reliable or sensible explanation exists. $^{21}$ The ostensible reason for this perspective is the fear that such reliance will make people with transsexualism particularly vulnerable to eugenic practices that would eliminate transsexualism if a biological/genetic marker for transsexualism were identified. $^{22}$ While this is perhaps a reasonable apprehension, it does not justify a refusal to provide a reasonable explanation for transsexualism when one exists; especially when that biological explanation positions transsexualism squarely within the intersexual continuum and clearly distinguishes transsexualism from trans and transgender, as well as the disorder diagnoses Gender Dysphoria and Gender Identity Disorder; while reinforcing the claims of people with transsexualism to equal and complete civil and human rights, including in respect of diagnosis and treatment.

While people with transsexualism have been quietly seeking to be assimilated within the life of the general community, trans, transgender and Intersex lobby groups have been visible, active and effective. Hence the popular community consultation acronym "GLBTI” for Gay, Lesbian, Bisexual, Transgender, Intersex. While it is important enough to distinguish gay, lesbian and bisexual sexualities here, transsexualism is presumed to get a voice in the generalised "transgender" or the medical construct and politically exclusive "Intersex". In these circumstances,

\footnotetext{
${ }^{18}$ Ibid xxiii.

${ }^{19}$ For another interesting discussion of such terminology, see Milton Diamond, 'Sex and Gender are Different: Sexual Identity and Gender Identity are Different' (2000) 7 Clinical Child Psychology \& Psychiatry 320. Also see the discussion by Leslie Feinberg in the Preface to her book, Transgender Warriors (1996).

${ }^{20}$ See the discussion of expert evidence in Re Kevin [2001] FamCA 1074, [209] to [273]; and particularly that of Professors Louis Gooren and Zhou and others discussed at [239] to [264] thereof.

${ }^{21}$ For example, Claire McNab. Vice-President, Press for Change (UK), 'The Life and Times of the Sliced Transsexual Brain', Available on-line at: <http://www.pfc.org.uk/congress/abstr6/abs-042.htm>. This was a paper delivered at The $6^{\text {th }}$ International Congress on Sex and Gender Diversity, 'Reflecting Genders', School of Law, Manchester Metropolitan University, $10^{\text {th }}$ to $12^{\text {th }}$ September 2004.

${ }^{22}$ Ibid.
} 
the distinct voice and needs of people living with transsexualism have often been lost or ignored.

Medical discourse concerning transsexualism came to be dominated by Freudian inspired psychiatry and psychoanalysis which, while offering no sustainable explanation for the existence of transsexualism and psychiatry's inability to 'treat'/eliminate/fix the phenomenon, objectified, pathologised and infantilised the people who experienced it; in the process projecting a genitocentric biological fundamentalism that proceeded to dominate the law in respect of transsexualism as epitomised by the English decision of Justice Ormrod in Corbett $v$ Corbett (orse Ashley). ${ }^{23}$

The genitocentric determination of the 'biological' or 'true' $\operatorname{sex}^{24}$ of a human being espoused in Corbett still seems to attract the fervent disparate support of such folk as the radically religious and the radically feminist. The one uniting factor or opinion at work here, and which was the cornerstone of the Corbett decision and the subsequent chain of decisions that relied upon the legal and scientific legitimacy of Corbett, is the proposition that the biological 'truth' of an individual human being's sexual identity may be discerned by only one means - the appearance of the person's genitalia at birth - no matter what the individual says of her/his own sexual identity, the evidence for the sexual differentiation of the human brain, what changes occur to the individual's body (including the genitalia) during a lifetime or how that lifetime is lived. Even though the decision in Corbett espouses a 'biological' test involving the assessment of a person's chromosomal sex and internal and external genitalia (only) at or near the birth event (only), the real predominance of genitalia in Ormrod J's consideration is confirmed by his emphasis upon the functionality of female genitalia and the decision's refusal to apply the same test to, or to deal with, the question of the common law sex of people with conditions of genital intersex.

The normative presumption that one is the sex indicated by one's genitalia is a subtle and deep-seated one. Even legislation drafted to enable people with transsexualism to re-assign their legal sex to bring it into conformity with their surgically affirmed sex commonly define sex affirmation surgery in terms of '...assisting a person to be considered to be a member of the opposite sex... ${ }^{25}$; where 'opposite sex' is used to denote a presumed pervasive biological truth

\footnotetext{
${ }^{23}$ [1971] P. 83 ('Corbett').

24 'Sexual identity' is either subsumed in or presumed by 'biological sex' or assigned to the distinctly mysterious and unreliable realm of individual 'psychology' as that term is used in Corbett and other similar genitocentric traditions.

${ }^{25}$ For an example, see Births, Deaths And Marriages Registration Act 1995 (NSW) s 32A. Note the mistaken lobbyist inspired use of the term "transgender" therein instead of transsexualism. It is clear that the legislation was not intended to deal with people other than those who had undergone sex affirmation surgery defined as 'a surgical procedure involving the alteration of a person's reproductive organs carried out: (a) for the purpose of assisting a person to be considered to be a member of the opposite sex, or (b) to correct or eliminate ambiguities relating to the sex of the person.'
} 
evidenced by the original assignment of a person's sex usually based solely upon the appearance of external genitalia.

The determination of the biological sex of an individual whose external genitalia have an appearance at birth which is sexually inconsistent with the individual's chromosomal formation and/or gonads or which has the characteristics of both male and female genitalia, is problematic under this genitocentric regime and is said to be neither male nor female but rather hermaphroditic; more recently termed 'Intersex' This limited approach, which is inconsistent with the culture's insistence on people being either male or female, caused problems too for courts charged with the determination of whether such an individual was legally male or female; when at law there is no 'third' or 'other' legal space available in terms of sexual identity. ${ }^{26}$

Until recently, this genitocentric vision of biological sex and sexual identity has so dominated our cultural psych, that transsexualism, as an example of intersexual variation in human sexual formation with no gross genital insignia, simply did not exist as a recognised biological, physiological or organic phenomenon and no language, whether medical or cultural, existed with which to describe it thus.

While the discourse of expert medical science was, by the commencement of the $R e$ Kevin proceedings, clearly speaking of intersexual phenomena in general, and transsexualism in particular, as examples of diversity in human sexual formation rather than aberration or disorder, general medical and legislative language continues to be genitocentric and to distinguish 'psychological' from 'biological' in respect of sexual formation, determination and identity.

People with transsexualism, and especially children and adolescents, are still burdened with the misconceived, misleading and monistic psychiatric diagnoses of Gender Dysphoria or Gender Identity Disorder derived from the outdated medical presumption that the assertion by an individual of a sexual identity contrary to the sex indicated by their genitalia, gonads and chromosomes accompanied by a sustained and compelling expressed need to alter their bodies to obtain sexual harmony with that identity must indicate disorder and/or illness.

\section{How Do You Explain a Problem Like Transsexualism?}

Historically there have been three competing 'nature verses nurture' explanations advanced by medical science and psychiatry for the cause of transsexualism: ${ }^{27}$

\footnotetext{
${ }^{26}$ For two quite different judicial responses to this predicament, made without the benefit of the Re Kevin decisions, see the decisions in the (now discredited) Australian decision In_the Marriage of $C$ and $D$ (falsely called $C$ ) (1979) 35 FLR 340 (' $C$ and $D$ ') and the United Kingdom decision $W v W$ [2001] 2 WLR 673 (' $W v W$ ').

${ }^{27}$ Michel, C Mormont1 and J J Legros, 'A Psycho-Endocrinological Overview of Transsexualism' (2001) 145 European Journal of Endocrinology 365.
} 
- The Non-Conflictual Psychological Theory - where transsexualism is seen as a pathology (a mental illness, confusion or disturbance of a normal psychological development of sexual identity) where sexual identity is precociously fixed and untreatable except by assisting the sufferer to live as well as possible with the pathology from which he or she suffers; and

- The Conflictual Psychological Theory - where transsexualism is seen as a pathology (a mental illness, confusion or disturbance of a normal psychological development of sexual identity) where sexual identity is not fixed and continues to remain ambiguous throughout development and is thus treatable by psychotherapy; and

- The Biological Theory - whereby observations on the sexual dimorphic character of the brain in animal studies (and lately some human studies) together with more recent genetic and behavioural studies propose that a human being's sexual identity derives from the sexual differentiation of human brain as to either the male or the female sex, in the same way as the other sexually differentiated aspects of the human body such as the genitalia, and is fixed and unalterable by the completion of infancy at the latest irrespective of social environment;

Transsexualism as a particular category of pathology or mental illness ('gender dysphoria syndrome') was included in the United States of American Psychiatrist's Diagnostic and Statistical Manual of Mental Disorders, edn III (DSM-III) in 1980, but was then removed from the DSM-IV in 1994 when it was assimilated/subsumed into the more general category of sexual and gender identity disorders. This significant change in the way psychiatry perceived transsexualism coincided with the removal from the DSM (after significant political and medical lobbying) of homosexuality as a pathology or mental illness or disorder. ${ }^{28}$ The DSM-IV changed the professional psychoanalytic view that there was a difference between transsexualism and Gender Dysphoria/GID while at the same time providing a radically new differential diagnostic criterion for children and adults with transsexualism. $^{29}$

As a consequence of this alteration to the DSM, people who experience or exhibit all types of non-normal behaviour in respect of sexual and/or gender expression are now grouped together by psychiatry in the DSM-IV. ${ }^{30}$ In particular, this change to the DSM IV enabled psychiatry to continue to 'legitimately' treat (try to change to heterosexual/normal) homosexual children whose parents find their behaviour unacceptable; even though adult homosexuality can no longer be legitimately treated as a mental illness.

\footnotetext{
${ }^{28}$ Ibid.

${ }^{29}$ Ibid.

${ }^{30}$ Ibid.
} 
Thus, the criteria for the diagnosis of Gender Dysphoria /Gender Identity Disorder in childhood contained in the DSM IV includes children with severe mental disorders, those who merely transgress accepted norms of gender expression such as those who exhibit transgender/cross-dressing behaviour/effeminate/tomboyish and those who are homosexual as well as those who experience transsexualism. ${ }^{31}$ This consummate vagueness of diagnostic criteria permits psychiatrists to give the contradictory evidence (as they do in Re Alex) of the uncertainty of the diagnosis of Gender Dysphoria/Gender Identity Disorder in childhood and adolescence, and to express doubt as to whether a child with that diagnosis will develop adult transsexualism, simultaneously with their evidence of their regular successful diagnosis and treatment of transsexualism in children and adolescence.

The best of these practitioners will admit, as they did in Re Kevin, that in practice transsexualism is self-diagnosed and that its treatment is self-prescribed in that children, adolescents and adults living with transsexualism generally come to the medical practitioner seeking sex affirmation treatment. The psychiatrist fulfils the important role of 'gatekeeper' by ruling out other phenomena such as disorders, homosexuality and transvestism, rather than actually identifying the causation of a person's transsexualism. It is misleading and confusing to maintain a distinction between childhood and adult transsexualism and/or the possibility that there are varying degrees of a conglomerate phenomenon encompassing Gender Dysphoria /Gender Identity Disorder, transgender expression such as cross-dressing and transsexualism. Hence, the creation of such further misleading terms as Extreme Gender Identity Disorder and Extreme Gender Dysphoria by some experts seeking to deal with the inclusion of transsexualism within the diagnostic hotchpotch of Gender Dysphoria /Gender Identity Disorder.

In Re Alex, after expressing himself to be uncomfortable with the term 'disorder' as applied by the expert witnesses to Alex, Chief Justice Nicholson (as he then was) used the hybrid term, 'Gender Identity Dysphoria', ${ }^{32}$ and applied it as part of the title of the case. Any reading of the decision indicates, however, that of all the participants in Re Alex, Alex himself was the least confused (or dysphoric) about his sexual identity. Alex's natural life goals and plans (for a young male with transsexualism), as well as his understandable frustration, anger and distress experienced in the care of those who reject his maleness after leaving the supportive and affirming environment of his father's care, are given a pathological 'spin' by the psychiatric evidence in the case; which appeared to be uncritically accepted by the court.

Psychiatrists and psychologists have come to rely upon the DSM terminology, notwithstanding its defects and difficulties, so as to give legitimacy and

\footnotetext{
${ }^{31}$ The actual formulation of the DSM IV is quoted (uncritically) in Re Alex [2004] FamCA 297, [101] within the evidence of English psychiatrist, "DR C". Dr C appears from his evidence to espouse the generally conflictual pathological view of transsexualism, as he appears to see treatment to avert a young person's transsexualism as an option.

${ }^{32}$ Re Alex [2004] FamCA 297, [2].
} 
professional protection when diagnosing and treating transsexualism; especially in children. The reality is, however, that the truly important role performed by psychiatry and psychology in the medical treatment of transsexualism, in both adults and children, is to rule out disorder or illness as an explanation for the phenomenon. The psychiatric evidence in Re Kevin, for example, confirmed Kevin's transsexualism by satisfying itself that his experience of himself as male in the face of the evidence to the contrary was not as a result of mental ill health, confusion or delusion. ${ }^{33}$

The fact is that psychiatry, while 'observing' and interacting with transsexualism over many years, has never been able to either adequately explain or 'cure' it. The dominant role of the endocrinologist, rather than the psychiatrist, in the treatment of transsexualism has long been recognised. Given the serious and sometimes irreversible nature of sex affirmation treatment, it is necessary for psychiatry to play its role in limiting treatment for transsexualism to those who experience it and at the same time to assume more responsibility in the task of enabling all people with transsexualism (children and adults), their families and loved ones to experience the difference of transsexualism in a healthy way.

The fact is that transsexualism should no longer be diagnosed and treated as if it were a mental illness or disorder. There is a developing campaign supported by diverse human rights groups, people with transsexualism and members of the medical and legal professions to remove transsexualism from the DSM as was done with homosexuality. Certainly, people with transsexualism will tell you they have never experienced Gender Dysphoria or any confusion about, or unhappiness with, either their gender or sexual identity. On the contrary, the experience of transsexualism (in the absence of any other phenomena or illness) is the experience of certainty and congruity as to both such identities in spite of all else. This is not to say that Gender Dysphoria and/or Gender Identity Disorder does not exist as a pathology or disorder. It is only to say that it is mistaken to include transsexualism within the same ambit.

If there is dysphoria associated with the experience of transsexualism, it is the product, well known to many with disability, of the interaction between a person of difference and the culture expressed through conscious and unconscious prejudice.

It is hard to better the clarity and detail of the discussion of the competing expert explanations for transsexualism, including the phenomena of the sexual differentiation of the human brain, carried out by Justice Richard Chisholm in his reasons and decision in Re Kevin. ${ }^{34}$ For convenience I set out his Honour's primary conclusions in respect of that expert evidence in Appendix B which confirm and

\footnotetext{
${ }^{33}$ In Re Kevin [2001] FamCA 1074, Chisholm J quotes from the report Dr Cornelius Greenway at [46]: 'I do not believe that Kevin's perception of himself as a male is a result of a psychosis, nor of a delusional disorder. I do not believe that he is suffering from a body dysmorphic syndrome.'

${ }^{34}$ Re Kevin [2001] FamCA 1074, Chisholm J, particularly [239] to [264].
} 
explain the overwhelming dominance of the biological explanation of transsexualism in both medical science and the law.

There will be no conclusive 'scientific proof' of the causation of transsexualism until medical science can identify and ratify the sexual differentiation of the human brain and/or genetic identifiers for transsexualism in living human beings.

As the legal team in Re Kevin, Teresa Anderson and I did not set out to prove the biological/'brain sex' explanation of transsexualism, but to meet and overcome the so-called 'biological/true sex' genitocentric formula for determining the common law sex of an individual as established by Corbett. We sought to do this by showing that the psychological/disorder explanation for transsexualism, sustained more by prejudice, psychological practice and teaching than fact, was less likely to be true than the biological/'brain sex' one and that the decision of Corbett was fundamentally legally flawed. Once such propositions were accepted, it could follow quite simply and logically that the most likely explanation for transsexualism is that it is an intersexual condition; taking the human brain into equal account with other body parts.

As Justice Chisholm commented:

The traditional analysis that they are "psychologically" transsexual does not explain how this state came about. For example, there seems to be no suggestion in the evidence that their psychological state can be explained by reference to circumstances of their upbringing. In that sense, the brain sex theory does not seem to be competing with other explanations, but rather is providing a possible explanation of what is otherwise inexplicable. $^{35}$

And

I have by no means quoted from or summarised the whole of the evidence before me. However in my view it does, in the end, support the applicants' argument that it leads to a different view of transsexualism from the view that was manifested in Corbett. For Ormrod $\mathbf{J}$ and for many of the experts at the time, transsexuals suffered from a discontinuity between their biology and their psychology, whereas intersexed people experienced inconsistencies within or among their biological qualities. But I am satisfied that the evidence now is inconsistent with the distinction formerly drawn between biological factors, meaning genitals, chromosomes and gonads, and merely "psychological factors", and on this basis distinguishing between cases of intersex (incongruities among

\footnotetext{
${ }^{35}$ Ibid [252].
} 
biological factors) and transsexualism (incongruities between biology and psychology). $^{36}$

And

There is still doubt about precisely what characteristics of the brain are involved, how the development takes place, and the extent to which the development extends beyond the time of birth. However, whatever the answers to these questions might prove to be, in my view the evidence demonstrates (at least on the balance of probabilities), that the characteristics of transsexuals are as much "biological" as those of people thought of as inter-sex. The difference is essentially that we can readily observe or identify the genitals, chromosomes and gonads, but at present we are unable to detect or precisely identify the equally "biological" characteristics of the brain that are present in transsexuals. ${ }^{37}$

\section{And finally}

In my view the evidence is, in essence, that the experts believe that the brain development view is likely to be true, and they explain the basis for their beliefs. In the circumstances, I see no reason why I should not accept the proposition, on the balance of probabilities, for the purpose of this case. $^{38}$

I quote these passages of the Re Kevin at length here, approved by the Full Court of the Family Court of Australia, as they dispose of the surprising proposition that the formal legal recognition of the biological nature of transsexualism is somehow either unattainable or unimportant and that 'legal and social concepts of human rights' provide a surer path to the attainment of legal and social recognition, legitimacy and equity.

No decision of any superior court in the world has affirmed the human rights and the legitimacy of people living with transsexualism to the extent of the Re Kevin decisions.

\footnotetext{
${ }^{36}$ Ibid [270].

${ }^{37}$ Ibid [272].

${ }^{38}$ Ibid [248].
} 


\section{RE KEVIN}

The decisions in Re Kevin and the affirming decision of the Full Court of Family Court of Australia in Re Kevin-Full Court represent both a turning point, and a culmination, in the history of the development of the human rights of people living with transsexualism and their families; both in Australia and internationally.

I said publicly at the time that the decisions demonstrated the significant capacity of the Australian justice system to embrace difference. In Re Kevin, the Applicant husband and wife successfully contended that, notwithstanding the husband's transsexual background, the husband was entitled to be married as a man because he was a man within the meaning of that expression in s 46(1) of the Marriage Act and s 43 of the Family Law Act at the time of his marriage.

Justice Chisholm's original decision, granting a Declaration of Validity of Marriage was delivered on $12^{\text {th }}$ October 2001. The appeal before the Full Court of the Family Court of Australia was heard on $18^{\text {th }}$ and $19^{\text {th }}$ February 2002. The Full Court consisted of their Honours Chief Justice Nicholson and Justices Ellis and Brown. The Full Court of the Family Court of Australia delivered its decision on $21^{\text {st }}$ February 2003. In its judgment, the Full Court dismissed the appeal by the Attorney General for the Commonwealth of Australian, thoroughly reviewed the applicable evidence and legal issues and strongly affirmed the original decision.

Re Kevin declared the law of Australia to the effect that the question of whether a person is a man or a woman for the purpose of the marriage law of Australia is to be determined as at the date of the marriage, that there is no rule or presumption of Australian law that the question of whether a person is a man or a woman is to be determined by reference (only) to circumstances at the time of the person's birth and that the answer to the question of whether an individual is a man or a woman for the purposes of the marriage law of Australia involves a subtle determination taking into account all the relevant sex differentiating facts and circumstances of the individual's life. Anything to the contrary in the English decision of Corbett was declared not to represent Australian law.

It was the primary contention of the Attorney General for the Commonwealth in the case that the question of whether a person is a man or a woman for the purposes of the marriage law of Australia should be determined pursuant to the reasoning and the test of the congruence of an individual's gonads, genitalia and chromosomal features (alone) as assessed at birth (only) as espoused in the judgment of His Honour Mr Justice Ormrod in Corbett. The Corbett decision also established the unfortunate legal precedent for treating people with transsexualism differently from those who experienced other types of intersexual conditions; even where the same 
or similar life/human rights issues, such as the need for a declaration of the legal sex of an individual or the right of an individual to marry, were involved. ${ }^{39}$

As was noted by the Full Court in Re Kevin, the expert evidence in that case, and most of the recent cases dealing with the issue world-wide, contradicted the mental illness/disorder/psychological explanation for transsexualism and supported the biological explanation. Such evidence also contradicted the Corbett distinction between so called 'physical/genital intersex' and 'brain-body intersex'. The 2001 English decision of $W v W$ demonstrated the logical and ludicrous result of the continued legal application of that distinction; where aged shady memories of minor irregularities of infant genital formation, such as the size of genitalia, could determine whether or not an individual was to be legally characterised (or legally diagnosed) as experiencing either a genital/body intersexual condition or transsexualism and, hence, whether or not an individual could marry in her or his affirmed sex.

In $W v W$ the successful litigant, with an almost identical predicament to that of Mrs Bellinger, was successful in having her marriage declared valid in the United Kingdom, notwithstanding her genitalia were unambiguously male at birth and she possessed a ' $\mathrm{Y}$ ' chromosome, because the evidence was that her male genitalia could be said to have been smaller than 'the norm' at birth and a medical expert was able to retrospectively (she had undergone Sex Affirmation Surgery) hypothesise that she could have experienced a degree of Androgen Insensitivity Syndrome and it could thus be hypothesised that she experienced a traditionally recognised 'intersex' condition rather than transsexualism. I recall a news report at the time commented that in the case of $W v W$ '...size really did matter'. I would not wish to be seen to be critical of Charles $\mathbf{J}$ who gave this decision. His Honour was bound by United Kingdom precedent to follow the decision of Corbett. Aided by intelligent submissions on behalf of Mrs W, Charles J merely sought and found a tortuous but humane way to save Mrs W from the application of the arbitrarily cruel Corbett dictum; which essentially established a form of biological apartheid which ensured that people with transsexualism who had undergone Sex Affirmation Treatment were unable to marry at all.

Re Kevin has been relied upon in several landmark international decisions; including I $v$ The United Kingdom and Christine Goodwin v The United Kingdom, decided $11^{\text {th }}$ July 2002 by the European Court of Human Rights. These decisions, which quote Justice Chisholm's decision in Re Kevin at length and with approval, finally determined that there had been violations of articles 8,12, 13 and 14 of the Convention for the Protection of Human Rights and Fundamental Freedoms in respect of the legal status of people who had experienced transsexualism in the United Kingdom and, in particular, such people's treatment in the spheres of employment, social security, pensions and marriage. As a result of these decisions

\footnotetext{
${ }^{39}$ See $W v W$ [2001] 2 WLR 673 and Bellinger $v$ Bellinger [2001] 2 FLR 1048, and the discussion of these judgments in the Re Kevin-Full Court decision.
} 
the government of the United Kingdom introduced the Gender Recognition Act 2004.

The legal nexus between the Gender Recognition Act 2004 and the Re Kevin decisions really highlights the international interdependence of reform efforts in respect of the human rights of people with transsexualism. For reasons not altogether clear to me, the Re Kevin decisions seem to have received comparatively little favourable attention from activists for law reform for people living with transsexualism in the United Kingdom.

While there are several aspects of the Gender Recognition Act 2004 which give rise to some considerable concern, such as the use of Gender Dysphoria and Gender Identity Disorder as qualifying concepts, the use of the concepts of "gender" and "acquired gender" and its treatment of marriage, the Gender Recognition Act 2004 is a tremendous achievement for all those who worked towards its introduction when one considers that the legislation emerged out of a totally unsupportive common law environment. By way of contrast, and as is acknowledged by Chisholm J, Re Kevin and legislation throughout Australia dealing with the interests of people with transsexualism stand upon a solid common law foundation of cases and legal literature which have long rejected the Corbett approach and which had sought to deal with transsexualism in an inclusive and humane way. ${ }^{40}$

Re Kevin was again relied upon in the landmark decision of the Sixth Judicial Circuit In And For Pasco County, Florida, in the United States of America in The Marriage of Kantaras. ${ }^{41}$ At page 673 of his decision Justice O'Brien said: '....it is essential that Kevin (Re Kevin) not be given a mere "citation" but studied for what it represents in the law. It is one of the most important cases on transsexualism to come on the scene of foreign jurisprudence.'

The judgments in Re Kevin and Re Kevin-Full Court provide clear support for the proposition advanced by the expert evidence in the case that it is now reasonable to conclude the likelihood that, as for the animal brain, the human brain differentiates as to sex (female or male) in the same way as the other sexually differentiated features of the human body. ${ }^{42}$ That evidence and the findings expressed in both of

\footnotetext{
${ }^{40}$ The two leading cases are $R v$ Harris and McGuinness (1988) 17 NSWLR 158 (NSW Court of Criminal Appeal) and Department of Social Security v SRA (1993) 118 ALR 467 (Full Court of Federal Court of Australia).

${ }^{41}$ Case number 98-5375CA 511998DR00537WS. Kantaras has since been overturned on appeal and is likely to be the subject of a further appeal.

${ }^{42}$ See Appendix $\mathrm{C}$ for a diagrammatic representation of the process derived from the evidence of Professor Gooren given in Re Kevin. The Full Court of the Family Court was satisfied, as was Chisholm $\mathrm{J}$, that the scientific and medical evidence before the Court clearly showed that, on the balance of probability, transsexualism was to be regarded as a naturally occurring intersex condition properly and therapeutically treated by SAT (including SAS). For a detailed contemporary expert discussion of this subject, see Frank P M Kruijver, 'Sex in the Brain', a thesis conducted at the Netherlands Institute for Brain Research, Amsterdam, the Netherlands published October 2004 with the support of the Netherlands Institute for Brain Research.
} 
these judgments in respect of the nature of transsexualism can be summarised as follows:

- The phenomenon of transsexualism arises as a result of the once off sexual differentiation of the human brain that occurs at odds with the balance of the sexually differentiated features in the formation of a human being and is a natural variation in human sexual formation and not a mental illness or disorder;

- Transsexualism is a form of intersex; ${ }^{43}$

- An individual's brain sex differentiation, or neurological sex, can not be changed by means of psychotherapy and is 'hardwired';

- People with transsexualism self-diagnose their condition; ${ }^{44}$

- Rather than diagnosing the condition of transsexualism, the important role played by psychiatry with regard to transsexualism is to ensure that people who experience mental disorders, such as delusional disorders, affecting gender identity, or who are transgender, do not receive sex affirmation treatment;

- $\quad$ The needs for sex affirmation and sex affirmation treatment by a person with transsexualism are not instances of desire or predilection, but rather are so compelling that the need to bring harmony between the life of sexual experience and the person's brain sex means that people who experience transsexualism are prepared to risk everything, including their livelihood, their family connections and their health, by undergoing sex affirmation treatment in order to bring that harmony about;

- That sex affirmation treatment, though including serious irreversible medical procedures, is rehabilitative for a person with transsexualism. Hence, the goal or purpose of sex affirmation treatment is not imitation of a cultural conception of the function or appearance of a perfect male or female body. The goal or purpose of sex affirmation treatment is the attainment of sexual unity and comfort by the person with transsexualism ${ }^{46}$.

The Full Court affirmed Chisholm J's approach in Re Kevin to the determination of the common law sex of a person for the purpose of marriage. His Honour's judgment set out a broad and undefined range of both biological and cultural characteristics of a person that should be taken into account in ascertaining the

\footnotetext{
${ }^{43}$ See Re Kevin-Full Court [2003] FamCA 94, [326] and post.

${ }^{44}$ This statement was also confirmed by Dr Russell Reid in his address at the 2004 Gendys Conference in the United Kingdom;

${ }^{45}$ See Re Kevin [2001] FamCA 94, [43] - [46].

${ }^{46}$ For a number of reasons set out in expert evidence, and in the husband's evidence, such as medical risk, present efficacy, cost and family obligation, Kevin, like many males experiencing transsexualism, had not undergone phalloplasty (penile construction) at the time of the hearing. The husband was still considered by the expert opinion, and the Respondent/Appellant, to have successfully undergone complete irreversible sex affirmation treatment; sufficient to permit medical certification pursuant to sections 32B and 32C of the Births, Deaths and Marriages Registration Act 1995 (NSW).
} 
person's common law sex ${ }^{47}$. Although his Honour cautioned that no list could be definitive, he highlighted the following aspects of a person as being the primary factors to be taken into account in such determination:

- the person's biological and physical characteristics at birth (including gonads, genitals and chromosomes);

- the person's life experiences, including the sex in which he or she is brought up and the person's attitude to it;

- the person's self-perception as a man or woman;

- the extent to which the person has functioned in society as a man or a woman;

- any hormonal, surgical or other medical aspects of sex affirmation treatment the person has undergone and the consequences of such treatment;

- the person's biological, psychological and physical characteristics at the time of the marriage, including (if they can be identified) any biological features of the person's brain that are associated with a particular sex.

At the same time, his Honour acknowledged that people with transsexualism who had undergone sex affirmation surgery would normally be considered as members of their affirmed sex at common law; whether or not their legal sex had been reassigned under State law.

It is possible to distil the following further principles from the Re Kevin decisions:

1. A person with transsexualism who has undergone irreversible sex affirmation treatment will normally be considered a member of their affirmed sex at common law;

2. Sex affirmation surgery does not have to meet any predetermined standards of either appearance or function in order to be considered 'successful' or to have occurred. The purpose of sex affirmation treatment (and sex affirmation surgery) is rehabilitative and for the benefit of the individual or subject, rather than imitative and for the benefit of the culture or observer;

3. The task of the law in determining the sex of a person for the purpose of marriage (and otherwise) is not that of determining the person's 'true sex' or predominant biological sex, but rather the sex, male or female, into which the person best fits having regard to the sexually differentiated characteristics of the person, the person's ability to function and live in either sex, the person's gender expression as well as cultural expectations of what it means to be a man/male or a woman/female person;

4. Australian culture conceives of people who have undergone irreversible sex affirmation treatment (including genital surgery) as being of their affirmed sex ${ }^{48}$

\footnotetext{
${ }^{47}$ See Appendix D for the full extract of [326] to [330] of the judgment headed 'Conclusion'.
} 
5. The question of the validity of a marriage is to be determined having regard to the various factors to be taken into account, including the sex of each of the parties to the marriage, at the time of the marriage (and not otherwise).

\section{Re Kevin As Part of a Common law Heritage}

Prior to the Re Kevin decisions, any discussion of the right of a person with transsexualism to marry, or to be legally recognised in accordance with their affirmed sex, would have begun with, or focused upon, the decision of Corbett. As demonstrated by Chisholm $\mathrm{J}$ in Re Kevin, however, Corbett did not actually represent either the orthodox or traditional common law opinion or position on the subject. The judgment of one of the earliest cases, In Re Leber (Switz-c1946) ('Re Leber'), establishes a tradition or approach, which I call "Inclusive", and which is consistent with Re Kevin, rather than Corbett, when it states

This inclines us to attribute to the psychic element, in the determination of sex, an importance at least equal to that of the physical element...It is not only the body which determines the sex of the individual, it is also the mind. When there is a discord between body and mind, one must see which of these two elements predominates. Leber...must be placed in the category of human beings, which he most resembles. ${ }^{49}$

It is that tradition, which seeks to include people with the intersexual difference of transsexualism into the legal world of male and female according to their affirmed neurological sex, that was maintained by Judge Pecora in the American decision of Re Anonymous ${ }^{50}$ where his Honour states

The Court is cognisant of the fact that the transsexual, anatomically, does not present the same problem as that of the pseudo-hermaphrodite. His social sex is determined by his anatomical sex. But again, by definition, his psychological sex, as distinguished from his anatomical sex, is that of the opposite sex. Absent surgical intervention, there is no question that his social sex must conform with his anatomical sex, his mental attitude notwithstanding. But once surgical intervention has taken place, whereby his anatomical sex is made to conform with his psychological sex, is not

\footnotetext{
${ }^{48}$ Contrast this conclusion with that of the House of Lords in the United Kingdom in Bellinger $v$ Bellinger [2003] 2 WLR 1174, where a contrary cultural observation was expressed. In Bellinger, however, unlike the Re Kevin decisions, there was no evidence before the Court of cultural opinion or perception. One could expect that if such evidence were before a court in the United Kingdom, it would show similar cultural perception.

${ }^{49}$ Re Kevin [2001] FamCA 1074, [111] - [115].

50293 NYS 2d 834 (1968) ('Re Anonymous-1968').
} 
his position identical to that of the pseudo-hermaphrodite who has been surgically repaired? Should not society afford some measure of recognition to the altered situation and afford this individual the same relief as it does the pseudo-hermaphrodite? ? $^{51}$

In these circumstances, it is the decision of Corbett which takes a different and radical position in which Ormrod $\mathrm{J}$, the medically qualified judge, brings his particular and strongly held views on biology and homosexuality to bear on the subject of transsexualism. As discussed and confirmed in both the Re Kevin decisions, Ormrod J's judgment lacks a cohesive logic and selectively adopts and rejects the expert evidence before him in order to create a narrow pseudo biological test so as to determine the 'true sex' of a person with transsexualism (only). Justice Ormrod is able to specifically preclude a person of transsexual background, and not a person with genital intersex, from marrying in their affirmed sex, by limiting the application of his pseudo biological test to the time of the birth event. One piece of evidence his Honour was obliged to exclude was the evidence that people with transsexualism experienced an intersexual condition. This pseudo 'biological test' is expressed by Justice Ormrod in this famous quotation from his decision:

...the criteria must, in my judgment, be biological, for even the most extreme degree of transsexualism in a male or the most severe hormonal imbalance which can exist in a person with male chromosomes, male gonads and male genitalia cannot reproduce a person who is naturally capable of performing the essential role of a woman in marriage. ${ }^{52}$

A characteristic of most of the cases that follow and adopt the Corbett pseudo 'biological' test, other than because of precedent, such as the decision of the Texas Court of Appeals in Littleton v. Prange, ${ }^{53}$ is their uncritical acceptance of the certainty and correctness of the Corbett approach; essentially based upon the proposition that transsexualism is a form of mental ill-health or psychological disorder. I describe the approach therein adopted as the "Exclusive" approach.

It is possible to identify a version or variation of this approach, which is still fundamentally based on a belief in the 'disorder model' of transsexualism, evidenced by Littleton as well as by the majority decisions in United Kingdom case of Bellinger ${ }^{54}$ from the original trial, through the Court of Appeal, to the House of Lords. This sub-group, which I describe as ultimately adopting the "Exclusive-butToo Difficult-Anyway" approach, sometimes begin their decisions appearing to be Inclusive, but then politely question how a human being can actually "change the sex they are born with" and ultimately reach a decision denying inclusive rights to

\footnotetext{
${ }^{51}$ Ibid 837.

${ }^{52}$ Corbett [1971] P. 83 [106]

53 9 S.W.3d 223 (Tex. Civ. App. 1999), cert. denied 148 L. Ed. 2d 119, 121 S. Ct. 174 (2000) ('Littleton').

${ }^{54}$ At trial, [2001] 1 FLR 389, 402; Court of Appeal, [2001] EWCA Civ 1140, 17/7/01); House of Lords, [2003] 2 WLR 1174.
} 
people living with transsexualism; by first reciting a number of legal and social difficulties which they foresee would occur if they were to follow the inclusive path and then by reciting the litany that courts should leave such matters to the decision of Parliament. Such decisions recite this formula notwithstanding that they discuss, and rely upon, the decision of Corbett in which Ormrod $\mathrm{J}$ was more than happy to make a decision in respect of the same subject matter without reference to Parliament and saw clearly that it was the precise obligation of the Court to do so where Parliament had not prescribed otherwise within the relevant legislation; here the respective Marriage Acts. This is essentially the approach taken by the District Court of Appeal of Florida, Second District, in its decision reversing the trial decision of Justice O'Bryan in Kantaras. ${ }^{55}$

While the 1995 New Zealand decision Attorney-General v Otahuhu Family Court ${ }^{56}$ and the 2002 decisions of the European Court of Human Rights in I v The United Kingdom and Christine Goodwin v The United Kingdom reject the Corbett approach and determine that post-operative or surgically affirmed people with transsexualism should be able to marry in their affirmed sex, they do so without resolving the question of the causation of transsexualism and thus without providing any legitimacy for people with transsexualism in their affirmation of their sex. These decisions are based instead on a practical acceptance of the fact of sex affirmation surgery and the existence of people with transsexualism. They could be called the "Social Justice" cases. Although Chisholm J expressly acknowledged that he was not primarily relying upon his findings in respect of the nature of transsexualism in reaching his decision, he did seek to incorporate an appreciation of transsexualism within his decision rather than to disregard the issue or assign its resolution to some time in the future when medical science had placed the issue beyond doubt.

Apart from the first instance decision of Kantaras, the recent decision which most resembles the approach taken in the Re Kevin decisions is that of the Court of Appeal of the State of Kansas, in Estate of Gardiner ${ }^{57}$ where the Court also sought to pick up the inclusive approach pioneered in Re Leber and Re Anonymous-1968 by seeking to explore contemporaneous expert evidence concerning the sexual differentiation and formation of human beings so as to seek to ground the legal decision concerning the right of people with transsexualism to claim the legal sex they affirm in reference to medical science and the experience of people with transsexuals in contrast to the blinkered certainty of the Exclusive-but-Too-DifficultAnyway approach. As discussed in the Re Kevin-Full Court judgment, once the connection between transsexualism and other intersexual conditions is acknowledged, the United Kingdom decision of Charles $\mathrm{J}$ in $W v W$ can be appreciated as fitting squarely within the Inclusive line of cases.

The heritage of Australian decisions in respect of transsexualism, namely Harris and McGuinness and SRA, shows the evolutionary connection between the Social

\footnotetext{
${ }^{55}$ Case number 2D03-1377 judgment delivered 23rd July 2004.

${ }^{56}$ [1995] 1 NZLR 603.

${ }^{57}$ No 85,030, 11 May 2001, Court of Appeals of the State of Kansas.
} 
Justice and Inclusive decisions which preceded, and enabled, the Re Kevin decisions.

The common ground shared by the Social Justice and Inclusive cases is the requirement that a person living with transsexualism must first have physically affirmed their sex by way of undergoing irreversible sex affirmation treatment (including surgery) before that person can be legally recognised as being of the person's affirmed sex; although the Re Kevin and the Kantaras (first instance) decisions give a new and more humane meaning to that surgical requirement. While some remain critical of any surgical requirement, and while I believe legislation should provide for a compassionate exception to that requirement where age or health mean the undergoing of such treatment/surgery is impossible, I otherwise recognise that if people living with transsexualism desire full legal recognition in their affirmed sex, then they are obliged to recognise the need to fulfil minimal cultural expectations in respect of the different strength and sexual capacity of male and female bodies. It is one thing to have a right; but it is another equally important thing to have that right culturally received and acknowledged. Subject to the proper funding of sex affirmation treatment by the state, those people with transsexualism who are able to undergo such treatment will do so irrespective of the law.

\section{The Decision in Re AleX}

As I am unable to find a sensible place for this case within any of the lines of cases discussed above, and given the particular importance of the rights of children living with transsexualism, I will give this case special treatment.

At the same time, I do not intend to introduce into the discussion of this case issues concerning Australia's international treaty obligations in respect of children's rights, but rather to critique the decision within the same parameters as have been applied to the discussion of other decisions within this article. That is not to say, however, that such international children's rights considerations are not relevant to a consideration of Nicholson CJ's judgement in Re Alex.

Re Alex dealt with the issue of the right of an adolescent to obtain medical treatment for transsexualism. Such an issue poses a number of legal and ethical issues because of the competing interests of the various stakeholders. ${ }^{58}$ Such stakeholders include the child or adolescent, the child or adolescent's parents or guardians, the treating physician/s as well as the state (or culture). ${ }^{59}$

\footnotetext{
${ }^{58}$ H G Beh and J H Pietsch, 'Legal Implications Surrounding Adolescent Health Care Decision-Making in Matters of Sex, Reproduction and Gender' (2004) 13 Child and Adolescent Psychiatric Clinics of North America 675.

${ }^{59}$ Ibid 675-9.
} 
In $\boldsymbol{R} \boldsymbol{e}$ Alex the Family Court of Australia was thus obliged to ascertain and reflect a number of stakeholder interests in circumstances where those interests were subject to the changing perceptions and sensibilities of Australian culture and medical science in respect of transsexualism. Those primary interests can be identified as individual privacy, the rights of children and adolescents to autonomy in respect of sexual identity and medical treatment, the rights of parents to determine the welfare of their children and, in particular, the medical treatment to be afforded to their children and the right of the state, acting through the court, to protect children and adolescents in respect of certain special medical procedures which the court finds that children should not undertake without the court having first assessed the best interests of the child or adolescent on a case-by-case basis.

At the time of the hearing, Alex was a 13 year old asserting and affirming his male sex notwithstanding that he possessed a female anatomy and had been originally assigned to the female legal sex. The evidence was that Alex was sane and did not experience a disorder (other than transsexualism as therein characterised), had long sustained a consistent male sex affirmation and was properly diagnosed as experiencing transsexualism. This was made clear notwithstanding the dominance of psychiatric pathological terminology in the case. Surprisingly, in one of only two cursory references to Re Kevin in the decision, his Honour represents Re Kevin as authority for the proposition that the causation of transsexualism is uncertain. ${ }^{60}$

Regrettably, given the expert evidence and findings of Kevin, the expert evidence adduced in respect of transsexualism in Re Alex was limited to psychiatric opinion which adhered to the psychiatric/disorder model or explanation of transsexualism. That anachronistic perception of transsexualism dominates Re Alex from the very title of the case to the lengthy and misconceived public policy pronouncements concerning the law in respect of the re-assignment of legal sex as determined by birth certificate legislation with which it ends.

The reasoning of the decision, its legal and public policy ramifications and its treatment outcome for Alex give rise to considerable concern. Re Alex is a useful lesson for those dealing with issues of difference in legal proceedings. The concepts of the biological/intersexual model of transsexualism and the fallibility of the method we use to allocate legal sex in our culture, though previously individually touched upon, were clarified in the Re Kevin decisions as a result of the breadth, quality and interdisciplinary character of the expert evidence adduced in that case. Further, Re Kevin can be distinguished as a case in which people living with transsexualism were advised and represented by people living with transsexualism. A legal representative living with transsexualism should be better able to advocate the experience of transsexualism with clarity and conviction in the face of mixed or contrary expert opinion and cultural prejudice, ignorance and/or confusion in respect of the phenomenon.

\footnotetext{
${ }^{60}$ Re Alex [2004] FamCA 297, [192].
} 
The difference in the expert evidence and submissions concerning transsexualism in Re Kevin and Re Alex is important to the ultimate decision in Re Alex because the court findings as to the nature of transsexualism in childhood and adolescence, and hence the nature of the medical treatment for the condition, were crucial to the court's findings that Alex could not have the personal capacity to understand and consent to that treatment and that the treatment itself was a special medical procedure to which Alex's guardian was unable to consent; giving jurisdiction to the court in respect of the authorisation of such medical treatment. In so doing, the court assigned the treatment of transsexualism in adolescence to the same category as sterilisation for the mentally ill child and other such procedures, which have no therapeutic benefit for the young person concerned and thus present the possibility of a parent/child conflict of interest.

In Re Alex, the court reached the view that Alex should receive only some of the medical treatment he requested for his transsexualism because, as he suffered from "Gender Dysphoria/GID" as described by "Dr C", there was a reasonable chance that he would not go on to experience transsexualism as an adult. Notwithstanding, the court, even on an interim basis, permitted Alex to publicly affirm his sex and live his life, including attending school, as a young adolescent male. At the same time the court limited the treatment options open to Alex's treating doctors necessary to enable him do so with anything other than a neo-pubertal female body. Further, the orders ultimately made by Nicholson CJ appear to anticipate the ongoing participation of the court in decision-making concerning Alex's ongoing medical treatment until adulthood utilising the Child Representative. It is difficult to find the justification for the costs incurred by this ongoing intrusion by the court into Alex's medical treatment, or to imagine individual parents, or legal aid, footing the bill for such ongoing legal participation in medical treatment decisions for every young person in Australia requiring treatment for transsexualism. One only has to review Kevin's evidence in Re Kevin concerning the agony of adolescence for a young person with transsexualism to imagine the unnecessary difficulties and pain this tentative, complex, costly and delay-prone approach to the treatment of transsexualism in adolescence must deliver to Alex.

Although a pre-eminent treatment centre for children with transsexualism has existed in the Netherlands for some years, where treatment for transsexualism in childhood and adolescence is part of an established and monitored program, no evidence from that treatment centre was produced for Re Alex. If such evidence and the evidence of the routine non-surgical treatment of other children with intersexual conditions had been before the court in Re Alex there must be doubt that the court could have found either Alex's request for treatment for transsexualism, or the treatment itself, 'novel'. ${ }^{61}$ This statement or conclusion is also hard to reconcile with the fact his Honour should have been aware that "Dr C" had treated a considerable number of young people in respect of transsexualism in the United Kingdom.

\footnotetext{
${ }^{61}$ Re Alex [2004] FamCA 297, [174]-[200] and particularly [180].
} 
I have already received instructions from parents of a 12 year old affirmed female with transsexualism in New South Wales who must now deal with the determination of NSW Health that the decision in Re Alex requires that her parents obtain the approval of the Family Court of Australia for the medical treatment she promptly requires when, prior to that decision, no such court approval was necessary and the treatment had been medically approved in accordance with the Children and Young Persons (Care and Protection) Act 1998 (NSW). I am instructed that there are several other young people and their families similarly adversely affected by the Re Alex decision in New South Wales alone. As the effects of shame and cultural prejudice subside, it is likely more young people with transsexualism will be able to access help and medical treatment with the assistance, approval and support of their families and the community. I submit that it is neither good medical practice, humane (to the child and her or his family) nor good public policy that the medical treatment of each such child or young person be subject to the delay, worry and cost of obtaining the approval of the Family Court of Australia. The additional financial and other impositions involved in the process of court approval are likely to result in further professional reluctance to diagnose, and further parental resistance to both diagnosis and treatment.

In Re Kevin and Re Alex it could be said that the Family Court of Australia has now apparently accepted two conflicting explanations for transsexualism. On another view, Re Alex demonstrates the misconceived differentiation between transsexualism in childhood/adolescence and in adults that is evidenced in the DSM. In my opinion Re Alex should be distinguished, and the explanation of transsexualism in Re Kevin preferred for all who experience it, in circumstances where the quality and breadth of the expert evidence relied upon in Re Alex is questionable and the fact that such expert evidence does not appear to have been challenged or tested in the particular circumstances, and management, of that case. There also appears to have been a failure of adequate submissions dealing with a number of issues as commented upon by his Honour in the judgment or as otherwise referred to herein. Moreover, the judgment in Re Alex takes on the demeanour of reformist zeal in arguing in favour of the abandonment of the requirement of sex affirmation treatment as a precondition of the reassignment of legal sex. In doing so, the court may have adopted the transgender perspective that sex affirmations surgery is an optional choice for people living with transsexualism rather than the essential medical treatment that it is.

My contentions in respect of the legal aspects of the decision in Re Alex grounding jurisdiction can be summarised as follows:

1. The decision was given per incuriam in that, in circumstances where there is a significant difference of expert opinion in respect of the nature of transsexualism in childhood/adolescence (as to whether it is a natural intersexual variation in human sexual formation as found in $\operatorname{Re} \operatorname{Kevin}^{62}$ in respect of transsexualism generally or whether it is a mental illness,

\footnotetext{
${ }^{62}$ Re Kevin [2001] FamCA 1074, [270] - [273].
} 
psychological disturbance, disorder or state of mental confusion), his Honour only had the benefit of limited expert opinion of a psychiatric nature which only informed the court of one these opinions in circumstances where:

1.1 Such expert opinion was crucial to the court's categorisation of the phenomenon of transsexualism in childhood/adolescence and the categorisation of its medical treatment and hence the court's decision as whether such treatment had, or had not, a therapeutic purpose as well as whether such medical treatment was, or was not, intended for the benefit of the child/adolescent;

1.2 The expert evidence before the court in Re Alex in respect of the nature and (certainty of) diagnosis of transsexualism in childhood/adolescence was essentially in conflict with common sense and the extensive expert evidence and findings of the Re Kevin decisions.

1.3 The limited and arguably inadequate nature of the expert evidence as to the phenomenon of transsexualism in childhood and adolescence, its diagnosis and its medical treatment upon which the court relied in Re Alex brings into question the courts determination of its jurisdiction in the case.

2. The Court's significant jurisdiction to usurp the power of a child's parents/guardian in respect of the authorisation of medical treatment is not exercised or invoked lightly or for every medical treatment or procedure that has irreversible and possibly dire consequences. The principles, which the court in Re Alex purports to follow, were set out by the High Court concerning the Family Court's child welfare/parens patriae powers in Secretary, Department of Health and Community Services $v$ JWB and SWB. ${ }^{63}$ That case involved the sterilisation of an intellectually disabled child/adolescent where the sole or predominant purpose of the medical procedure in question was the young person's sterilisation.

3. In Marion's Case, the High Court went to some length to stress that its decision did not mean that the power of a parent or guardian to authorise medical treatment for a child was usurped by the court where sterilisation (or any other 'invasive, permanent and irreversible medical treatment') was a likely or possible by-product of medical treatment carried out for a therapeutic purpose. To be a special medical procedure, the medical procedure or treatment involved had to have the special character of having no therapeutic benefit for the child or young person receiving it;

\footnotetext{
${ }^{63} 175$ CLR 218 ('Marion's Case').
} 
4. At paragraph 152 and following of the judgment in Re Alex, his Honour confirmed that if the Family Court were to have jurisdiction in respect of the Re Alex proceedings, the court first had to determine whether Alex had capacity to consent to such procedure himself (as per the Gillick Test ${ }^{64}$ ). If Alex had that capacity, the Family Court had no jurisdiction in the case. His Honour then confirmed that, in the event that Alex did not have that capacity, the Family Court would only have jurisdiction in the case if the proposed medical procedure was a Special Medical Procedure as defined in Marion's Case. If Alex had capacity to consent and/or the proposed procedure was not a Special Medical Procedure, then the court had no jurisdiction.

5. At paragraph 153 of the Re Alex decision his Honour extracted the gravamen of Marion's Case in respect of the determination of when a medical procedure is special in so far as normal parental consent is ineffective or insufficient consent as being when the proposed medical procedure:

5.1 Is invasive, permanent and irreversible; and

5.2 Is not for the purpose of curing a malfunction or disease.

6. With the respect due to his Honour, I contend there was error in applying the principles referred to above, and in Marion's Case, in respect of the determination of Alex's capacity to consent (particularly at paragraphs 157 to 173) when he finds that although Alex apparently passes the Gillick test of personal understanding/appreciation and/or capacity, the nature of the 'sex change' procedure is such that no child/adolescent could have the requisite capacity to consent to such treatment. While it is contended that his Honour's judgment on this issue must have been influenced by the limited evidence which dominated Re Alex concerning transsexualism in childhood, its diagnosis and treatment, it is wrong to apply the principles espoused both in Marion's Case and the Gillick test to the determination of the question of Alex's personal capacity to consent, by transforming the personal nature of that assessment to one applicable to any and all children/adolescents in respect of the medical treatment of transsexualism.

7. I also question the finding of his Honour at paragraphs 174 through to 200 that the treatment for Alex's transsexualism (referred to misleadingly and anachronistically as 'sex change') was not for the purpose of curing a malfunction or disease (ie was not therapeutic). Thus, his Honour characterised treatment for transsexualism in childhood/adolescence as the same as medical treatment carried out with the purpose of sterilising a child; where the consent of a parent was insufficient due to a possible conflict of interest between parent and child.

\footnotetext{
${ }^{64}$ The principle, approved by the High Court in Marion's Case, expressed in the House of Lords decision in Gillick v West Norfolk and Wisbech Area Health Authority 1986 AC 112 ('Gillick's Case') that determined the competency of a child or young person to give informed consent to a medical procedure where there was otherwise no legislative determination of the question.
} 
8. The literature on the subject indicates that the earlier people (especially children/adolescents with transsexualism) receive treatment the better the chances of the success of such treatment and the better the overall quality of their lives. ${ }^{65}$ Evidence of the existence of an urgent need for Alex to receive treatment was before his Honour. Thus, I believe there was a failure in the decision to take account of the financial, emotional and child welfare implications of the decision on the parents of children/adolescents with transsexualism; and hence the adverse affect of the decision upon children/adolescence with transsexualism themselves in likely limiting and delaying their opportunity and access to treatment. These were considerations clearly present in the decision of the High Court in Marion's case which led that court to so limit the medical treatment that could be classified or categorised as a Special Medical Procedure and which should have led his Honour in Re Alex to find that the treatment of transsexualism in childhood/adolescence was not.

Notwithstanding my criticism of the decision in Re Alex, the fundamental goodwill and open-mindedness exhibited by Nicholson CJ is the distinguishing characteristic of our Australian justice system that enables it to deal so well with diversity and which provides its capacity to facilitate cultural maturation. The errors, which I contend are present in the decision, indicate, however, that special considerations are required when having difference on trail if we are to do justice to minorities within our culture.

It is therefore important to emphasise that my criticism of the evidence, submissions and the decision of the Family Court of Australia in Re Alex neither makes or implies a criticism of the medical experts and lawyers who participated in those proceedings. Indeed, the goodwill, earnest intent and efforts of those people to seek and obtain a result in the case that honoured Alex and was in his best interests is abundantly clear. There was no conscious or individual prejudice at work in $R e$ Alex that could be held responsible for the error of the decision in that case. There is prejudice in $R e$ Alex, but being cultural prejudice it is so deep-rooted, selfreinforcing, almost 'natural' and pervasive that its presence is camouflaged. The responsibility for that prejudice belongs to us all, is cultural, and is the product of the difficulties to be met when the law seeks to deal with an unusual aspect of ourselves that we have long sought out of fear to deny; in this case transsexualism.

\section{CONCLUSION}

Re Kevin is the clear statement of Australian common law confirming the method of the determination of the sex of an individual who has experienced the intersex

\footnotetext{
${ }^{65}$ Cohen-Kettenis and Pfafflin, above n 12, 140-1.
} 
condition of transsexualism for the purpose of marriage. The decision continues and expresses a long international common law tradition of cases dealing with transsexualism in a culturally inclusive way. In its expert and detailed exploration of transsexualism as an example of the human condition, it is a general teaching, as much as a legal judgment, and represents the foundation of a new era in human rights for people who experience a phenomenon which has been so mystified and misunderstood. Re Kevin is also an evidentiary blueprint to those representing people living with transsexualism (and other aspects of difference); and particularly in cases where regard may be had to the cultural perception of people with transsexualism and/or statutory interpretation requiring the determination of the ordinary, everyday meaning of words in legislation.

Re Kevin is a credit to the courage and determination of the applicants, 'Kevin' and 'Jennifer' and the workings of Australian justice that enabled them to succeed against a committed Commonwealth government to establish a true 'landmark' in the movement for equal civil rights for people living with transsexualism. The considerable lay evidence of 'Kevin's' acceptance as a man in Australian culture and the overwhelmingly positive acceptance of the decision is a welcome reminder of the intrinsic compassion of Australians and our desire and capacity to give the 'underdog' a go.

Re Kevin confirms the Australian cultural acceptance and appreciation of diversity or difference in human sexual formation. The decision confirms the expert opinion that biological sex is multi-dimensional and is ultimately determined by the sexual differentiation of the human brain rather than by body parts such as external genitalia. It is now clear that a person's legal sex (as per their birth certificate) can be different from their predominant biological or innate sex (as per their 'brain sex') as well as their common law sex as determined by a court. Our society has now begun to understand transsexualism and some other traditionally known intersex conditions, to appreciate the life experience of the people who live with these conditions and that such conditions are nothing more or less than natural variations in human sexual formation.

Is now possible to distinguish an individual's gender expression (or gender identity) from the individual's sex (or sexual identity) and to appreciate that both are different again from an individual's sexuality as indicated by the terms "homosexual", "bisexual" and "heterosexual". In so doing it is easier to understand the essential need of an individual who experiences transsexualism to affirm his or her innate sex by undergoing conclusive sex affirmation procedures and then to have his or her legal sex reassigned to secure the issue of an appropriate birth certificate to secure the right of accurate non-discriminatory identity and full uncompromised legal rights in the individual's reassigned legal sex in congruity with the affirmed sex and sexually rehabilitated/harmonised body. The need for uniform State and Territory legislation guaranteeing these fundamental human rights is now clear and yet no such uniform legislation exists. 
As people with transsexualism have been increasingly 'reading themselves aloud' ${ }^{66}$ over the past decade, and as transsexualism has increasingly been recognised in Australia and elsewhere as a biologically derived intersexual condition with an established diagnosis and treatment regime, the demands have intensified for the full recognition of the fundamental human rights of people who experience transsexualism such as the right:

- to be diagnosed as experiencing transsexualism and treated without being medically classified as suffering a mental illness or disorder such as Gender Dysphoria and Gender Identity Disorder;

- to be accorded equality of legal rights with others who experience intersexual conditions in respect of access to medical treatment and the reassignment or correction of an individual's legal sex;

- of children and adolescents with transsexualism (and their parents) to receive personal, medical and legal support for the affirmation of their innate sex so as to be able upon diagnosis to promptly (without court approval) undergo various non-surgical aspects of sex affirmation treatment so as to forestall the development of inappropriate and harmful secondary sexual characteristics and to enable such children to experience their adolescence with physical characteristics appropriate to their affirmed sex;

- to receive medical treatment for the condition funded by the state as for any other critical medical condition;

- of a person of transsexual background (one who has undergone irreversible sex affirmation treatment so as to physically affirm her or his sex) to have that person's legal sex altered so as to accurately reflect that person's physically affirmed sex and sexual identity without the precondition of having to end an existing marriage and so as to provide for full and unconditionally equal rights in the individual's affirmed sex;

- of a person with transsexualism who, as a result of age or health, is unable to undergo complete irreversible sex affirmation treatment, to be assessed by an expert panel and, in appropriate circumstances, to be permitted the reassignment of legal sex on a compassionate and/or provisional basis;

- of a person of transsexual background to participate in competitive sport in the person's affirmed sex; and

- of a person of transsexual background to otherwise have the right to live a full and fulfilling life in the person's physically affirmed sex on the same terms as others of that sex in respect of such issues as superannuation and other forms of insurance without discrimination.

I am a believer in the maxim that the degradation of the existence of the least of us degrades the existence of us all. We can each have more meaningful and proactive lives through our everyday dealings with each other by showing the kind of understanding and acceptance of difference and imperfection in the people we meet

\footnotetext{
${ }^{66}$ Stone, above n 3, 299.
} 
that will help create a world in which we can be comfortable with our own. The creation of beauty out of imperfection is, after all, our human heritage.

Transsexualism is a profound example of human difference that has the power to teach us about our relationship with difference per se. The recognition of the human rights of people living with transsexualism calls upon us to reach out with an open mind in order to stake our claim in own humanity through the appreciation of human lives so different from our own. I am convinced that our own lives become richer through this reception of the lives of our brothers and sisters in difference and that it is this capacity for the reception and appreciation of difference that is the way forward that the people of our planet must take in order to prevail. These sentiments reflect those embodied in the words of author and United Nations UndersecretaryGeneral for Communications and Public Information, Shashi Tharoor, when he said

If the 20th Century can be said to be the one in which the world was made safe for democracy, let it be said that the 21 st Century was the one in which the world was made safe for diversity. ${ }^{67}$

\footnotetext{
${ }^{67}$ Based upon the author's notes of a ABC Radio National interview conducted by Shashi Tharoor broadcast in about January 2003.
} 


\section{APPENDIX A}

\section{DIFFERENCE AND FOREGOING PASSING - Circa 1991}

Transsexuals who pass seem to be able to ignore the fact that by creating totalised, monistic identities, foregoing physical and subjective intertextuality, they have foreclosed the possibility of authentic relationships. Under the principle of passing, denying the destabilising power of being "read", relationships begin as lies - and passing, of course, is not an activity restricted to transsexuals. This is familiar to the person of color whose skin is light enough to pass as white, or to the closet gay or lesbian ... or to anyone who has chosen invisibility as an imperfect solution to personal dissonance... I could not ask a transsexual for anything more inconceivable than to forego passing, to be consciously "read", to read oneself aloud - and by this troubling and productive reading, to begin to write oneself into the discourses by which one has been written - in effect, then, to become a (look out - dare I say it again?) posttranssexual...*

* (an extract from) Sandy Stone, 'A Post transsexual Manifesto', in Julia Epstein and Kristina Straub (Eds) Body Guards (1991) 298-9. 


\begin{abstract}
X Appendix B
Re Kevin - Significant findings of Justice Richard Chisholm in respect of the expert medical evidence in that case as to the causation of transsexualism and as strongly affirmed by the Full Court on appeal
\end{abstract}

At paragraph [247]: 'In my view the expert evidence in this case affirms that brain development is (at least) an important determinant of a person's sense of being a man or a woman. No contrary opinion is expressed. All the experts are very well qualified. None was required for cross-examination, nor was any contrary evidence called'.

At paragraph [248]: 'In my view the evidence is, in essence, that the experts believe that the brain development view is likely to be true, and they explain the basis for their beliefs. In the circumstances, I see no reason why I should not accept the proposition, on the balance of probabilities, for the purpose of this case.'

At paragraph [252]: "The traditional analysis that they are "psychologically" transsexual does not explain how this state came about. For example, there seems to be no suggestion in the evidence that their psychological state can be explained by reference to circumstances of their upbringing. In that sense, the brain sex theory does not seem to be competing with other explanations, but rather is providing a possible explanation of what is otherwise inexplicable'.

At paragraph [253]: 'In other words (as I understand it) the brain of an individual may in some sense be male, for example, though the rest of the person's body is female'.

At paragraph [265]: "In my view the argument in favour of the "brain sex" view is also based on evidence about the development and experience of transsexuals and others with atypical sex-related characteristics. There is a vast literature on this, some of which is in evidence, and I can do no more than mention briefly some of the main points'.

At paragraph [268]: 'It seems quite wrong to think of these people as merely wishing or preferring to be of the opposite sex, or having the opinion that they are'.

At paragraph [270]: 'But I am satisfied that the evidence now is inconsistent with the distinction formerly drawn between biological factors, meaning genitals, chromosomes and gonads, and merely "psychological factors", and on this basis distinguishing between cases of inter-sex (incongruities among biological factors) and transsexualism (incongruities between biology and psychology)'. 
At paragraph [272]: 'In my view the evidence demonstrates (at least on the balance of probabilities) that the characteristics of transsexuals are as much "biological" as those of people thought of as inter-sex'.

At paragraph [136]: 'I agree with Ms Wallbank that in the present context the word "man" should be given its ordinary contemporary meaning. In determining that meaning, it is relevant to have regard to many things that were the subject of evidence and submissions. They include the context of the legislation, the body of case law on the meaning of "man" and similar words, the purpose of the legislation, and the current legal, social and medical environment. These matters are considered in the course of the judgment. I believe that this approach is in accordance with common sense, principles of statutory interpretation, and with all or virtually all of the authorities in which the issue of sexual identity has arisen. As Professor Gooren and a colleague put it: -

"There should be no escape for medical and legal authorities that these definitions ought to be corrected and updated when new information becomes available, particularly when our outdated definitions bring suffering to some of our fellow human beings".' 


\section{APPENDIX C}

\section{Human Sex Differentiation Time Line}

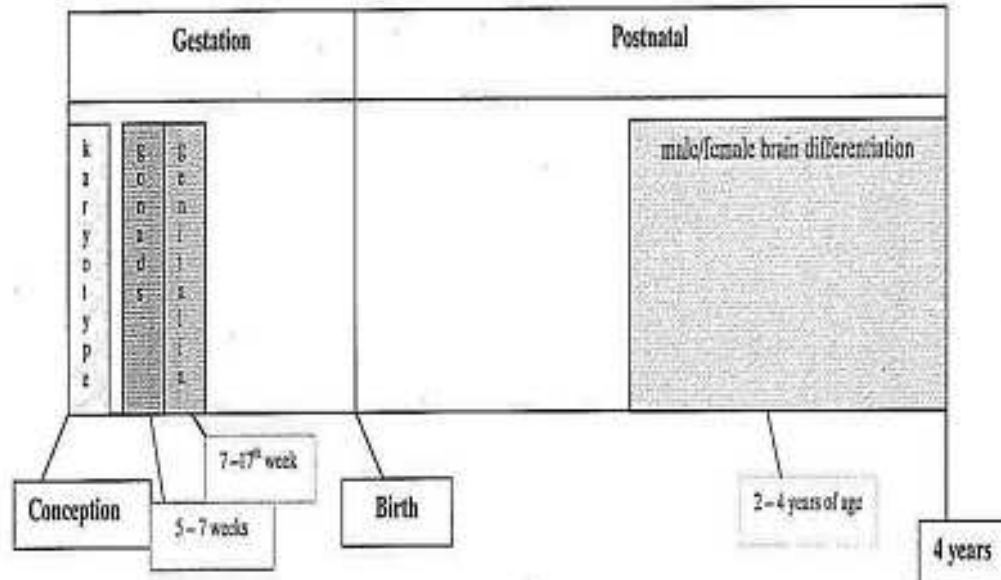

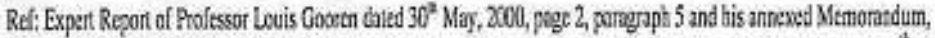

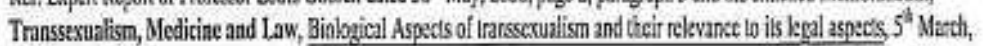
1993, poges $16 \cdot 18$ 


\section{APPENDIX D}

\section{The Conclusions of Justice Richard Chisholm in Re Kevin}

[326] Although the extensive evidence and argument required this judgment to be of considerable length, in my view there are overwhelming reasons why the application should be granted. I see no basis in legal principle or policy why Australian law should follow the decision in Corbett. To do so would, I think, create indefensible inconsistencies between Australian marriage law and other Australian laws. It would take the law in a direction that is generally contrary to developments in other countries. It would perpetuate a view that flies in the face of current medical understanding and practice. Most of all, it would impose indefensible suffering on people who have already had more than their share of difficulty, with no benefit to society.

[327] I do not agree with Mr Burmester that a decision in favour of the applicants is ground-breaking, or anything of that sort. It is true that this judgment canvasses some interesting new medical evidence, and that the discussion of legal principle has been wide-ranging. While I have made findings about the medical evidence and offered a view about the underlying basis for such decisions as Corbett, the end result does not depend on acceptance of either of these matters. Ultimately, the basis for this judgment is very simple and mundane. It is that no good reasons have been shown why the ordinary legal meaning of the word "man", which includes post-operative female to male transsexuals, should not also apply to marriage.

[328] Because the words "man and "woman" have their ordinary contemporary meaning, there is no formulaic solution to determining the sex of an individual for the purpose of the law of marriage. That is, it cannot be said as a matter of law that the question in a particular case will be determined by applying a single criterion, or limited list of criteria. Thus it is wrong to say that a person's sex depends on any single factor, such as chromosomes or genital sex; or some limited range of factors, such as the state of the person's gonads, chromosomes or genitals (whether at birth or at some other time). Similarly, it would be wrong in law to say that the question can be resolved by reference solely to the person's psychological state, or by identifying the person's "brain sex". 
[329] To determine a person's sex for the purpose of the law of marriage, all relevant matters need to be considered. I do not seek to state a complete list, or suggest that any factors necessarily have more importance than others. However the relevant matters include, in my opinion, the person's biological and physical characteristics at birth (including gonads, genitals and chromosomes); the person's life experiences, including the sex in which he or she is brought up and the person's attitude to it; the person's self-perception as a man or woman; the extent to which the person has functioned in society as a man or a woman; any hormonal, surgical or other medical sex reassignment treatments the person has undergone, and the consequences of such treatment; and the person's biological, psychological and physical characteristics at the time of the marriage, including (if they can be identified) any biological features of the person's brain that are associated with a particular sex. It is clear from the Australian authorities that post-operative transsexuals will normally be members of their reassigned sex.

[330] I state my conclusions in this case as follows: -

1. For the purpose of ascertaining the validity of a marriage under Australian law, the question whether a person is a man or a woman is to be determined as of the date of the marriage.

2. There is no rule or presumption that the question whether a person is a man or a woman for the purpose of marriage law is to be determined by reference to circumstances at the time of birth. Anything to the contrary in Corbett does not represent Australian law.

3. In the context of the rule that the parties to a valid marriage must be a man and a woman, the word "man" has its ordinary current meaning according to Australian usage.

4. There may be circumstances in which a person who at birth had female gonads, chromosomes and genitals, may nevertheless be a man at the date of his marriage. Anything to the contrary in Corbett does not represent Australian law.

5. In the present case, the husband at birth had female chromosomes, gonads and genitals, but was a man for the purpose of the law of marriage at the time of his marriage, having regard to all the circumstances, and in particular the following: -

(a) He had always perceived himself to be a male;

(b) He was perceived by those who knew him to have had male characteristics since he was a young child;

(c) Prior to the marriage he went through a full process of transsexual reassignment, involving hormone treatment and irreversible surgery, conducted by appropriately qualified medical practitioners; 
(d) At the time of the marriage, in appearance, characteristics and behaviour he was perceived as a man, and accepted as a man, by his family, friends and work colleagues;

(e) He was accepted as a man for a variety of social and legal purposes, including name, and admission to an artificial insemination program, and in relation to such events occurring after the marriage, there was evidence that his characteristics at the relevant times were no different from his characteristics at the time of the marriage;

(f) His marriage as a man was accepted, in full knowledge of his circumstances, by his family, friends and work colleagues.

6. For these reasons, the application succeeds, and there will be a declaration of the validity of the applicants' marriage. 